\title{
LMP1 and LMP2A are potential prognostic markers of extranodal NK/T-cell lymphoma, nasal type (ENKTL)
}

Yuan Mao ${ }^{1}$, Da-Wei Zhang ${ }^{2}$, Huijun Zhu ${ }^{3}$, Hong Lin ${ }^{4}$, Lin Xiong ${ }^{5}$, Qing Cao ${ }^{2}$, Ying Liu' ${ }^{1}$, Qing-Dong Li ${ }^{1}$, Jia-Ren Xu ${ }^{6 *}$, Lin-Feng $X^{7^{*}}$ and Ren-Jie Chen ${ }^{2^{*}}$

\begin{abstract}
Background: Latent membrane protein (LMP) 1 and LMP2A encoded by Epstein-Barr virus (EBV) are associated with the development of malignancies, but their expression in extranodal NK/T-cell lymphoma, nasal type (ENKTL) and the relationship with clinical characteristics of this disease remain poorly understood. In the present study, we examined the expression of LMP1 and LMP2A in ENKTL, and investigated the correlations between LMP1 and LMP2A expression with clinicopathological characteristics of ENKTL patients.

Methods: Paraffin sections of surgically removed samples from 16 ENKTL patients were analyzed by immunohistochemistry and the related clinicopathological data were collected and analyzed.

Results: Elevated expression (immunohistochemistry score $\geq 4$ ) of LMP1 and LMP2A was detected in the tumor cells of ENKTL. High LMP1 expression was associated with positive B symptoms $(p=0.012)$, while high LMP2A expression was related to gender $(p=0.029)$. The expression of both LMP1 and LMP2A showed significant correlations with patients' overall survival $(p=0.049, p=0.036)$.
\end{abstract}

Conclusion: LMP1 and LMP2A may be prognostic indicators of survival in patients with ENKTL.

Virtual slides: http://www.diagnosticpathology.diagnomx.eu/vs/2443352538545899

Keywords: LMP1, LMP2A, EBV, ENKTL, Prognosis, Tumor marker

\section{Introduction}

Extranodal NK/T-cell lymphoma, nasal type (ENKTL) is recognized as a distinct clinical pathological entity of non-Hodgkin's lymphoma, and develops more frequently in East Asia and Central America than in the West [1,2]. ENKTL was previously described as lethal midline granuloma or midline reticulosis, which most commonly invades the nasal cavity and other mucosal sites of the upper aerodigestive tract. Although ENKTL can be diagnosed at early stage, it is characterized by a strongly aggressive lymphoma

\footnotetext{
*Correspondence: xujiaren@tom.com; xulinfeng@medmail.com.cn; renjiechenent@yahoo.com.cn

${ }^{6}$ Department of Hematology and Oncology, Jiangsu Provincial Hospital, No.65 Jiangsu Road, Nanjing 210029, China

${ }^{7}$ Department of General Surgery, The Second Affiliated Hospital of Nanjing Medical University, No.121 Jiang jia yuan, Nanjing 210011, China

${ }^{2}$ Department of Otolaryngology-Head and Neck Surgery, The Second Affiliated Hospital of Nanjing Medical University, No.121 Jiang jia yuan, Nanjing 210011, China

Full list of author information is available at the end of the article
}

in advanced stage and resistance to different treatments [3]. Currently, ENKTL is mainly treated by concurrent chemoradiotherapy [4-6], but the overall survival is frustratingly poor [7]. Among the risk factors of ENKTL development, Epstein-Barr virus (EBV) latent infection has been shown to play an important role, and ENKTL is closely associated with EBV infection [8-11].

EBV is a member of the g-herpes- virus family which approximately infects $90 \%$ of the adult population in the world. A variety of molecules are involved in EBV latent infection, including EBV-encoded nuclear antigens (EBNAs); EBNA leader protein (EBNA-LP); latent membrane protein (LMP) 1, LMP2A, and LMP2B; and EBV encoded RNAs (EBERs) EBER1 and EBER2 [12]. Among these, LMP1 is essential for EBV-mediated growth transformation of infected cells, and the C-terminal region of LMP1 protein can regulate a variety of cellular signaling pathways such as TNF receptor, NF- $\mathrm{kB}$ and JAK/STAT

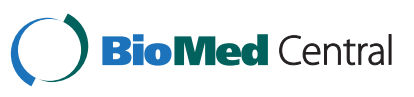


to regulate the proliferation, immortalization, and invasion of lymphoma cells [13-15]. Therefore, LMP1 has been suggested to have oncogenic effects in the development and progression of EBV-related lymphomas. On the other hand, LMP2A is one of the most commonly present EBV encoding proteins and is widely expressed in EBV-infected cells within the infected human host and EBV-associated malignancies. LMP2A is the only one membrane protein expressed in the reservoir of circulating, latently EBV-infected resting B-cells [16]. LMP2A contributes to malignant transformation by intervening with multiple signaling pathways, especially the cell cycle and apoptotic pathways, thus plays important role in viral latency and tumorigenesis $[17,18]$. The ability of LMP2A to influence the balance of survival factors in B lymphocytes could be functionally important in Burkitt lymphoma and LMP2A expression in EBV-infected B cells may lead to the induction and maintenance of an activated, proliferative state that could ultimately result in the development of Hodgkin lymphoma $[19,20]$. However, the correlation between the expression of LMP1 and LMP2A in ENKTL and patient prognosis is poorly understood.

In this study, we examined the expression profiles of LMP1 and LMP2A in ENKTL patients by immunohistochemistry analysis. Moreover, we analyzed the correlation of LMP1 and LMP2A expression with the clinicopathologic features and outcomes of ENKTL. Our results suggest that LMP1 and LMP2A are potential biomarkers for the diagnosis and prognosis of patients with ENKTL.

\section{Materials and methods \\ Patients and diagnosis}

Total 16 cases of ENKTL were enrolled in this study who were diagnosed at Department of Pathology, the Affiliated Hospital of Nantong University between 2005 to 2011. All 16 cases were histologically confirmed, with complete clinical information and follow-up data. The pathologic diagnosis and classification of ENKTL was based on the criteria described previously [1,21]: 1) current World Health Organization classification; 2) the histologic characteristics of ENKTL; 3) EBER expression by in situ hybridization; 4) the expression of CD3 (T cell markers) and CD56 by immunohistochemistry; 5) the absence of B cell phenotype with CD20. Cases which were negative for CD56 while positive for both cytotoxic markers and EBER were also categorized as ENKTL. Written informed consent was obtained from the patient for publication of this report and any accompanying images. Study protocol was approved by the Ethics Committee of Jiangsu Province Official Hospital.

Table 1 Clinical and histologic features of 16 patients with ENKTL

\begin{tabular}{|c|c|c|c|c|c|c|c|c|c|c|c|}
\hline $\begin{array}{l}\text { Patient } \\
\text { no. }\end{array}$ & Age & Sex & $\begin{array}{l}\text { Primary } \\
\text { sites }\end{array}$ & $\begin{array}{c}\text { Ann Arbor } \\
\text { stage }\end{array}$ & $\begin{array}{l}\text { LDH } \\
\text { level }\end{array}$ & $\begin{array}{c}\text { B } \\
\text { symptoms }\end{array}$ & IPI & Therapy & $\begin{array}{l}\text { Response to } \\
\text { treatment }\end{array}$ & $\begin{array}{l}\text { LMP1 } \\
\text { expression } \\
\text { (IHS) }\end{array}$ & $\begin{array}{c}\text { LMP2A } \\
\text { expression } \\
\text { (IHS) }\end{array}$ \\
\hline 1 & 36 & $M$ & Nasal cavity & $\|$ & Normal & Positive & $\mathrm{LI}$ & $\mathrm{CHOP}+\mathrm{FLAG}$ & $P R$ & 6 & 6 \\
\hline 2 & 36 & $M$ & Oropharynx & III & High & Positive & $\mathrm{HI}$ & $\mathrm{CHOP}$ & $P R$ & 4 & 2 \\
\hline 3 & 57 & $M$ & Nasal cavity & $\|$ & Normal & Negative & $\mathrm{HI}$ & Surgery + CHOP & $C R$ & 2 & 1 \\
\hline 4 & 55 & $M$ & Larynx & I & Normal & Positive & $\mathrm{LI}$ & Surgery + CHOP & $P R$ & 8 & 1 \\
\hline 5 & 49 & $\mathrm{~F}$ & Nasal cavity & $\|$ & High & Negative & $L$ & Surgery & NR & 1 & 4 \\
\hline 6 & 51 & $M$ & Nasal cavity & 1 & High & Negative & $\mathrm{LI}$ & CHOP + Radiotherapy & $P R$ & 2 & 1 \\
\hline 7 & 67 & M & Nasal cavity & $\|$ & Normal & Positive & $\mathrm{HI}$ & $\mathrm{CHOP}+\mathrm{GDP}+\mathrm{CVAD}$ & $C R$ & 9 & 4 \\
\hline 8 & 25 & M & $\begin{array}{l}\text { Oropharynx, } \\
\text { palate }\end{array}$ & $\|$ & Normal & Negative & $L$ & CHOPE + ICE + Radiotherapy & $C R$ & 1 & 9 \\
\hline 9 & 71 & M & Nasal cavity & 1 & High & Positive & $\mathrm{LI}$ & $\mathrm{CHOP}+\mathrm{SMILE}$ & $C R$ & 4 & 2 \\
\hline 10 & 36 & M & Nasal cavity & $\|$ & Normal & Negative & $L$ & $\mathrm{CHOP}$ & $P R$ & 6 & 1 \\
\hline 11 & 63 & M & Nasal cavity & I & Normal & Negative & $L$ & CEVP + Radiotherapy & $P R$ & 2 & 1 \\
\hline 12 & 56 & M & Nasal cavity & $\|$ & Normal & Positive & $\mathrm{LI}$ & Surgery + CHOP & $P R$ & 3 & 2 \\
\hline 13 & 66 & $\mathrm{~F}$ & Larynx & $\|$ & High & Positive & $\mathrm{HI}$ & Surgery & $C R$ & 6 & 8 \\
\hline 14 & 47 & $M$ & Nasopharynx & 1 & Normal & Negative & $L$ & VEPA + Radiotherapy & $C R$ & 8 & 1 \\
\hline 15 & 51 & $\mathrm{~F}$ & Nasal cavity & III & Normal & Positive & $\mathrm{HI}$ & DICE + SMILE & $P R$ & 9 & 9 \\
\hline 16 & 27 & M & Nasal cavity & $\|$ & Normal & Negative & $\mathrm{LI}$ & Surgery + CHOP & $C R$ & 3 & 6 \\
\hline
\end{tabular}

LDH: lactate dehydrogenase; IPI: international prognostic index; IHS: immunohistochemistry score; LMP1: latent membrane protein 1; LMP2A: latent membrane protein 2A; L: low risk; LI: low-intermiediate risk; HI: high-intermiediate risk; CR: complete remission; PR: partial remission; NR: no response; CHOP: cyclophosphamide, hydroxydaunomycin, oncovin, prednisone; FLAG: fludarabine, arabinosylcytosine, granulocyte colony-stimulating factor; GDP: gemcitabine, dexamethasone, cisplatin; CVAD: cyclophosphamide, vindesine sulfate, adriamycin, cisplatin; CHOPE: cyclophosphamide, hydroxydaunomycin, oncovin, prednisone, etoposide; ICE: ifosfamide, cisplatin, etoposide; SMILE: steroid, methotrexate, ifosfamide, l-asparaginase, etoposide; CEVP: cyclophosphamide, epirubicin, vincristine, prednisone; VEPA: vincristine, cyclophosphamide, doxorubicin, predonisolone; DICE: dexamethasone, ifosfamide, cisplatin, etoposide. 


\section{Data extraction}

Clinical data of 16 cases were obtained from hospital medical records, which included age distribution, patient sex ratio, initial symptoms and signs, primary sites, Ann Arbor stage, lactate dehydrogenase (LDH) level, the presence of $\mathrm{B}$ symptoms, international prognostic index (IPI), therapy strategies (surgery, chemotherapy or radiotherapy), response to treatment and survival status.

\section{Histologic analysis}

ENKTL tissue sections were formalin fixed, paraffinembedded and H\&E-stained. The histopathological features of the cases were evaluated independently by two investigators.

\section{In situ hybridization}

EBERs in situ hybridization was performed on formalin-fixed paraffin-embedded tissue sections on 3aminopropyltriethoxy-silane (Sigma, St. Louis, MO, USA) treated slides using fluorescein isothiocyanateconjugated EBERs oligonucleotides as probes. Evaluation of hybridized sites was detected by anti-fluorescein isothiocyanate antibody labeled with alkaline phosphatase (Dako, Cytomation, Glostrup, Denmark), according to the manufacturer's protocols. The control procedures, including positive and negative control sections, were conducted simultaneously.

\section{Immunohistochemistry}

Paraffin tissue sections were deparaffinized in 100\% xylene and rehydrated in graded ethanol solutions. After

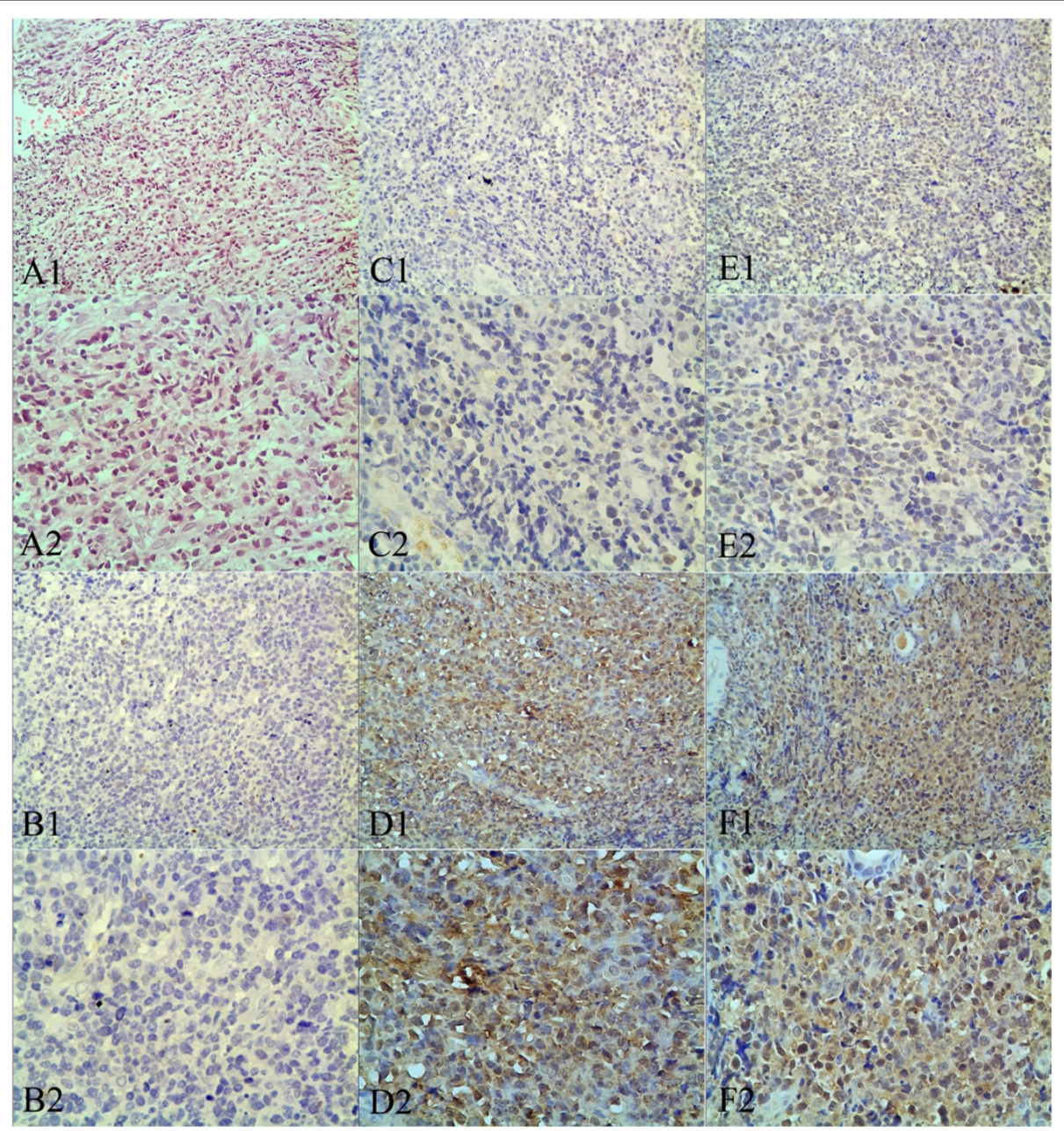

Figure 1 Immunohistochemical staining of LMP1 and LMP2A in clinical tissue samples of ENKTL. (A1 and A2) Hematoxylin-eosin staining of ENKTL tissue samples. (B1 and B2) Negative immunohistochemical staining of adjacent nontumorous tissue. (C1 and C2) Weak immunostaining of LMP1 in ENKTL tissue samples. (D1 and D2) Strong immunostaining of LMP1 in ENKTL tissue samples. (E1 and E2) Weak immunostaining of LMP2A in ENKTL tissue samples. (F1 and $\mathbf{F 2}$ ) Strong immunostaining of LMP2A in ENKTL tissue samples. Original magnification $\times 200$ in A1, B1, C1, D1, E1 and F1; $\times 400$ in A2, B2, C2, D2, E2 and F2. 
antigen retrieval the sections were immersed in a $0.3 \%$ hydrogen peroxide solution for 15 min to block endogenous peroxidase activity. Nonspecific binding was blocked by incubation with $5 \%$ goat serum in TBS for $30 \mathrm{~min}$. Tissue sections were then incubated with monoclonal antibodies anti-CD3 (Novocastra, Newcastle, UK), anti-CD20 (Dako), anti-CD56 (Dako), anti-TIA-1 (Abcam, Cambridge, UK), anti-LMP1 (Abcam) and antiLMP2A (Abcam), followed by incubation with EnVision horseradish peroxidase complex (DAKO). Negative controls were included by the replacement of the primary antibody with phosphate-buffered saline. Four fields in each slide were randomly selected and counted, the percentage of positive staining was determined using immunohistochemistry score (IHS) [22]. When a conclusion differed, the final decision was made by consensus. Results were analyzed according to the method described previously [23]. Briefly, IHS was determined by the evaluation of both staining density and intensity.
The percentage of positive tumor cells was scored as follows: 1 ( $0-10 \%$ positive cells), 2 (11-50\% positive cells), 3 (51-80\% positive cells), 4 (81-100\% positive cells); and the intensity of staining was scored as follows: 0 (negative), 1 (weakly positive), 2 (moderately positive), and 3 (strongly positive). Multiplication of the intensity and the percentage scores gave rise to the ultimate immunoreactivity score: samples with a sum score below 3 $(\mathrm{IHS} \leq 3)$ were judged as low protein expression, and those with a sum score above 4 ( $\mathrm{IHS} \geq 4$ ) as high protein expression.

\section{Statistical analysis}

Statistical analyses were carried out by using STATA Version 12.0 (Stata Corporation, College Station, TX) and SPSS 18.0 statistic software (SPSS Inc, Chicago, IL). The correlation of LMP1 and LMP2A expression with clinicopathological features of ENKTL was analyzed by chi-square test. Overall survival rate was estimated by

Table 2 Association of LMP1 and LMP2A expression with clinical characteristics and selected biological markers of ENKTL

\begin{tabular}{|c|c|c|c|c|c|c|c|}
\hline \multirow[t]{2}{*}{ Groups } & \multirow[t]{2}{*}{ No. } & \multicolumn{2}{|c|}{ LMP1 expression } & \multirow[t]{2}{*}{$p$ value } & \multicolumn{2}{|c|}{ LMP2A expression } & \multirow[t]{2}{*}{$p$ value } \\
\hline & & Positive & $\overline{\text { Negative }}$ & & Positive & $\overline{\text { Negative }}$ & \\
\hline \multicolumn{8}{|l|}{ Gender } \\
\hline Male & 13 & 7 & 6 & 0.687 & 4 & 9 & $0.029^{*}$ \\
\hline Female & 3 & 2 & 1 & & 3 & 0 & \\
\hline \multicolumn{8}{|l|}{ Age (years) } \\
\hline$\leq 40 y$ & 5 & 3 & 2 & 0.838 & 3 & 2 & 0.377 \\
\hline$>40 y$ & 11 & 6 & 5 & & 4 & 7 & \\
\hline \multicolumn{8}{|l|}{ Ann Arbor Stage } \\
\hline$|-| \mid$ & 14 & 7 & 7 & 0.182 & 6 & 8 & 0.849 \\
\hline||$|-| \mathrm{V}$ & 2 & 2 & 0 & & 1 & 1 & \\
\hline \multicolumn{8}{|l|}{ LDH level } \\
\hline High & 5 & 3 & 2 & 0.838 & 2 & 3 & 0.838 \\
\hline Normal & 11 & 6 & 5 & & 5 & 6 & \\
\hline \multicolumn{8}{|l|}{ B symptoms } \\
\hline Positive & 8 & 7 & 1 & $0.012^{*}$ & 4 & 4 & 0.614 \\
\hline Negative & 8 & 2 & 6 & & 3 & 5 & \\
\hline \multicolumn{8}{|l|}{$|P|$} \\
\hline Low/Low-intermediate & 11 & 5 & 6 & 0.197 & 4 & 7 & 0.377 \\
\hline High-intermediate/High & 5 & 4 & 1 & & 3 & 2 & \\
\hline \multicolumn{8}{|l|}{ Response to treatment } \\
\hline Complete remission & 7 & 4 & 3 & 0.493 & 4 & 3 & 0.319 \\
\hline Partial remission & 8 & 5 & 3 & & 2 & 6 & \\
\hline No response & 1 & 0 & 1 & & 1 & 0 & \\
\hline \multicolumn{8}{|l|}{ Prognosis } \\
\hline Live & 7 & 2 & 5 & $0.049^{*}$ & 1 & 6 & $0.036^{*}$ \\
\hline Dead & 9 & 7 & 2 & & 6 & 3 & \\
\hline
\end{tabular}


Kaplan-Meier method and statistical significance was assessed by the log-rank test. $\mathrm{P}<0.05$ was considered as statistical significance.

\section{Results}

Clinical features of ENKTL

The main clinicopathologic characteristics of patients with ENKTL were shown in Table 1. All ENKTL patients showed positive staining for CD3, TIA-1 and EBER-1 and negative staining for CD20. CD56 expression was present in $43.8 \%$ of 16 cases. There was a preponderance of male to female patients with a ratio of 13:3. The median age at diagnosis was 49.6 years (range 25-71 years). Among the 16 cases, 11 were in the nasal cavity, two in the oropharynx and/or palate, two in the larynx, and one in nasopharynx. Nasal obstruction was the most common initial symptom. According to the Ann Arbor stage of lymphoma, five patients were in stage I, nine in stage II and two in stage III of ENKTL. Five patients showed high LDH expression, and eight patients encountered B symptoms, including fever, night sweats, and weight loss. Furthermore, the IPI was used to predict the survival of patients with ENKTL. Most of the patients (11 of 16) presented low to intermediate risk, and the other five patients exhibited high to intermediate risk. Of all 16 ENKTL patients, six patients received chemotherapy, four patients received a combination of surgery and chemotherapy, four patients received a combination of chemotherapy and radiotherapy, and two patients received surgery alone. Seven patients experienced complete remission (CR) (43.8\%) and eight patients experienced partial remission (PR) (50.0\%), while one patient had no response (NR) (6.2\%).

\section{Expression of LMP1 and LMP2A in ENKTL}

LMP1 and LMP2A protein levels in ENKTL were examined using immunohistochemistry. High LMP1 expression was detected in nine (56.25\%) of 16 ENKTL tissues while high LMP2A expression was detected in seven $(43.75 \%)$ of 16 ENKTL tissues (Table 1). Typically observed immunohistochemical staining patterns for LMP1 and LMP2A were shown in Figure 1. For LMP1, positive staining was mainly localized in the cell membrane and cytoplasm, while for LMP2A, positive staining was mostly located in the cytoplasm. No immunostaining of LMP1 and LMP2A was observed in adjacent nontumorous tissues.

\section{Correlation between LMP1 and LMP2A expression with clinicopathological parameters of ENKTL}

The relationship between LMP1 and LMP2A protein levels with the clinicopathological parameters of 16 ENKTL patients was shown in Table 2. High LMP1 expression was associated with positive $\mathrm{B}$ symptoms $(\mathrm{p}=0.012)$ and patients prognosis $(0.049)$. No significant association was found between LMP1 expression and other clinical parameters, such as gender, age, Ann Arbor stage, LDH level, IPI or response to treatment. In contrast, high LMP2A expression was related to gender $(\mathrm{p}=0.029)$ and patients prognosis (0.036). No statistical association was shown between LMP2A expression and other clinical parameters, including age, Ann Arbor stage, LDH level, B symptoms, IPI or response to treatment (Table 2).

\section{Patients' survival}

Kaplan-Meier analysis of 16 ENKTL patients showed that the survival rate was significantly lower in patients with positive B symptoms, subjected to single therapy, or with high LMP1 and LMP2A expression. Log-rank test showed that positive B symptoms, treatment by single therapy, and high expression of LMP1 and LMP2A were associated with decreased overall survival of ENKTL patients $(\mathrm{P}=0.0180, \mathrm{P}=0.0082, \mathrm{P}=0.0201, \mathrm{P}=$ 0.0487) (Table 3, Figure 2).

\section{Discussion}

Most ENKTL cases show a uniform pattern of onset, typical pleomorphic morphology, and a similar NK cell immunophenotype. It is widely accepted that ENKTL is

Table 3 Survival analyses of prognostic factors in ENKTL

\begin{tabular}{lc}
\hline Variable & p value \\
\hline Gender & \\
$\quad$ Male versus Female & 0.0658 \\
Age (years) & 0.8679 \\
$\quad \leq 40 y$ versus >40y & \\
Ann Arbor Stage & 0.4129 \\
$\quad$ Stage I, II versus Stage III, IV & \\
LDH level & 0.7703 \\
$\quad$ High versus Normal & \\
B symptoms & $0.0180^{*}$ \\
$\quad$ Positive versus Negative & \\
IPI $\quad$ & 0.5418 \\
$\quad$ L/LI versus HI/H & \\
Treatment & $0.0082^{*}$ \\
$\quad$ Single therapy versus Combined therapy & \\
LMP1 expression & $0.0201^{*}$ \\
$\quad$ Positive versus Negative & \\
LMP2A expression & $0.0487^{*}$ \\
Positive versus Negative
\end{tabular}

LDH: lactate dehydrogenase; IPI: international prognostic index. L: low risk; LI: low-intermiediate risk; HI: high-intermiediate risk. ${ }^{*} \mathrm{P}<0.05$. 


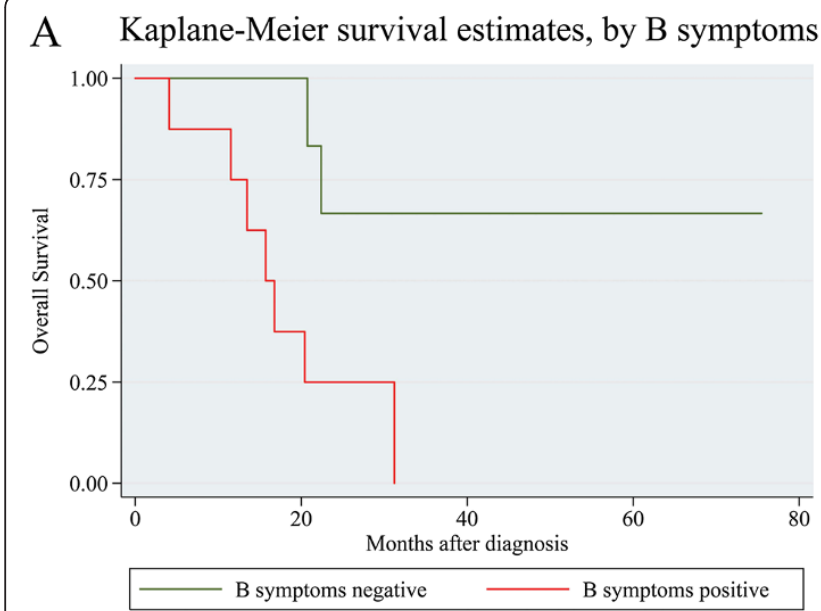

C Kaplane-Meier survival estimates, by LMP1

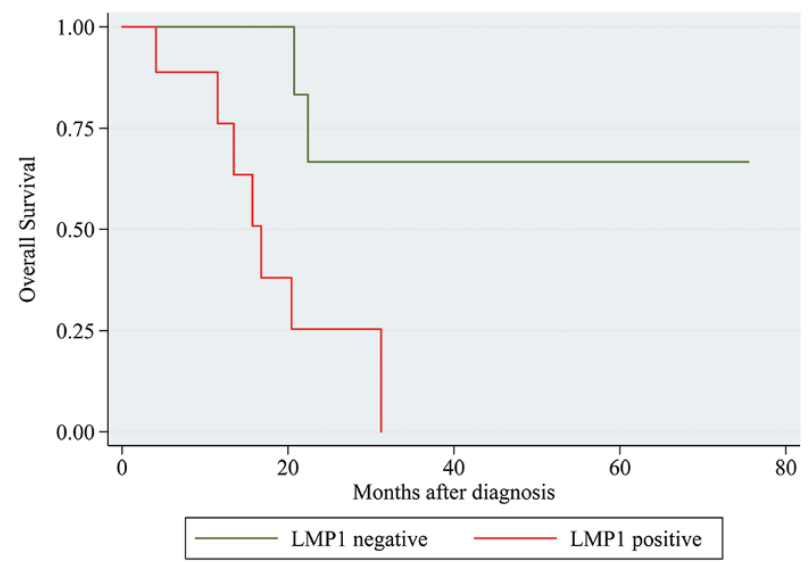

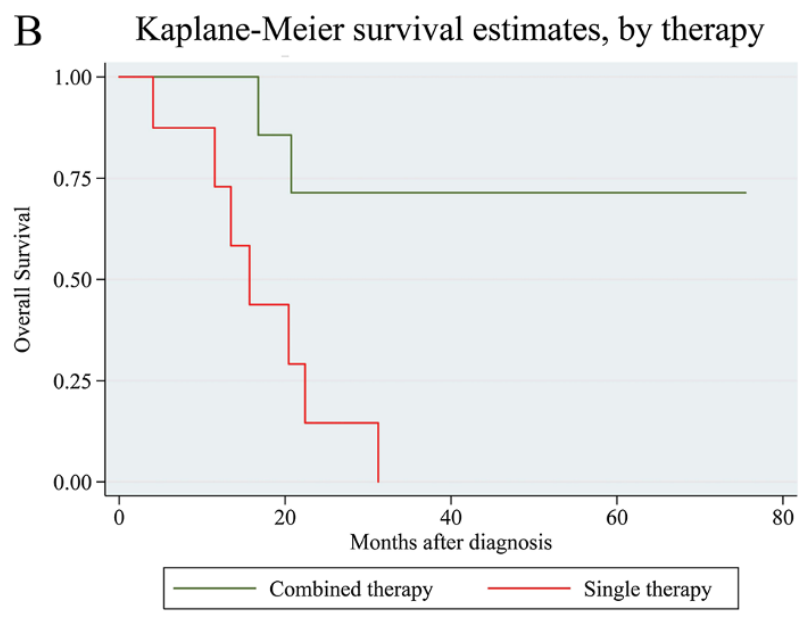

D Kaplane-Meier survival estimates, by LMP2A

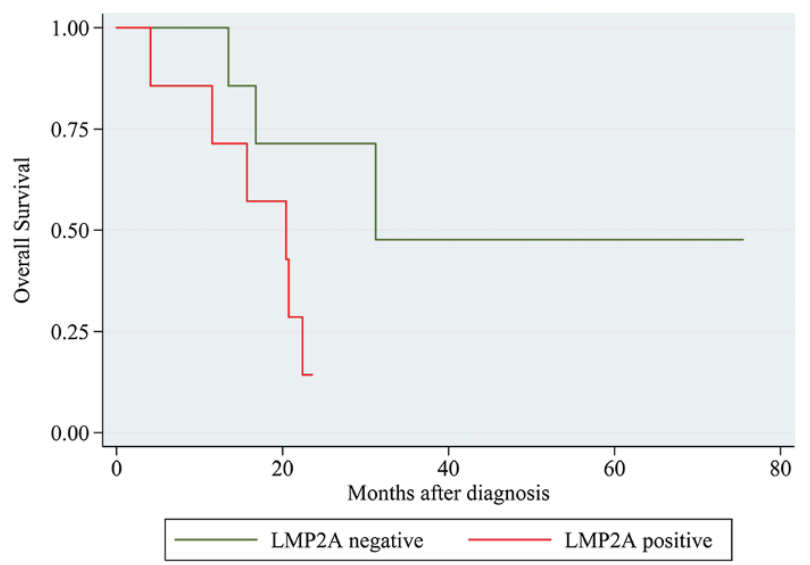

Figure 2 Analysis of the survival of ENKTL patients by Kaplan-Meier method. (A) Overall survival rate in patients with positive B symptoms (red line) was significantly lower than that in patients with negative B symptoms (green line). (B) Overall survival rate in patients with single therapy (red line) was significantly lower than that in patients with combined therapy (green line). (C) Overall survival rate in patients with positive LMP1 expression (red line) was significantly lower than that in patients with negative LMP1 expression (green line). (D) Overall survival rate in patients with positive LMP2A expression (red line) was significantly lower than that in patients with negative LMP2A expression (green line).

closely associated with EBV infection and abnormal expression of latent membrane protein products encoded by EBV [8-11]. Among these protein products, LMP1 is the most significant oncogenic protein which participates in the pathogenesis of EBV-associated lymphoma and is essential for EBV-induced B-cell transformation in vitro [12]. A variety of therapy strategies have been developed to target LMP1 or interfere with its downstream signal pathway, such as NF-kB, MAPK/MEK/ ERK and JAK/STAT pathway, to inhibit tumor growth [23-25]. LMP2A is generated by alternative splicing and the expression of LMP2A in EBV-infected B cells may lead to the induction and maintenance of an activated, proliferative state that could ultimately result in the development of EBV-related lymphoma [20]. LMP2A has been utilized for targeted therapy and immunotherapy for lymphoma [26-28]. However, the role of LMP1 and LMP2A in ENKTL remains unclear.

In the present study, we examined the correlation of LMP1 and LMP2A expression with clinical characteristics of 16 ENKTL patients. The results showed that 56\% (9/16) patients had positive LMP1 expression while 44\% (7/16) had positive LMP2A expression. Moreover, LMP1 expression was obviously related to the presence of $\mathrm{B}$ symptoms and patients' survival status, while LMP2A expression was related to gender and patients prognosis. It is interesting to notice that high expression of both proteins was correlated with poor prognosis. In addition, LMP2A expression appears to be related to gender. Although the relationship between LMP2A expression and gender was significant, we need to confirm it in later studies that enroll larger samples because only 3 female 
were enrolled in this study. Moreover, no statistical association was shown between LMP1 and LMP2A expression and other clinical parameters, including age, Ann Arbor stage, LDH level, IPI or response to treatment. Furthermore, Kaplan-Meier survival analysis showed that positive B symptoms, single therapy strategy and high expression of LMP1 and LMP2A could independently predict poor overall survival. These results are consistent with the regulatory effects of LMP1 and LMP2A on tumor cell growth, invasion, and metastasis reported in previous studies [14-17], and the poor prognosis of patients with high expression of LMP1 and LMP2A $[3,29]$.

However, due to small sample size of this study, further studies that employ larger scale of clinical samples of ENKTL will be important to confirm our findings, which will provide the judgment on the values of LMP1 and LMP2A proteins for the diagnosis and prognosis of ENKTL.

\section{Conclusion}

The expression of both LMP1 and LMP2A shows significant correlations with the prognosis of patients with ENKTL. LMP1 and LMP2A are novel prognostic markers of ENKTL.

\section{Competing interests}

The authors declare that they have no competing interests.

\section{Authors' contributions}

YM and $\mathrm{HL}$ carried out all evaluation, and YM drafted the manuscript. HJZ, DWZ and LX carried out the immunohistochemistry experiments and helped perform the evaluation. QC helped draft the manuscript. YL and QDL collected clinical data and participated in the evaluation of the immunohistochemistry. JRX, LFX and RJC contributed to the conception and design of the study. All authors read and approved the final manuscript.

\section{Author details \\ 'Department of Otolaryngology-Head and Neck Surgery, Jiangsu Provincial Hospital, No.65 Jiangsu Road, Nanjing 210029, China. ${ }^{2}$ Department of Otolaryngology-Head and Neck Surgery, The Second Affiliated Hospital of Nanjing Medical University, No.121 Jiang jia yuan, Nanjing 210011, China. ${ }^{3}$ Department of Pathology, Affiliated Hospital of Nantong University, No.20 Xisi Road, Nantong 226001, China. ${ }^{4}$ Jiangsu Provincial Blood Center, No.179 Longpan Road, Nanjing 210042, China. ${ }^{5}$ Department of Pathology, The Second Affiliated Hospital of Nanjing Medical University, No.121 Jiang jia yuan, Nanjing 210011, China. ${ }^{6}$ Department of Hematology and Oncology, Jiangsu Provincial Hospital, No.65 Jiangsu Road, Nanjing 210029, China. ${ }^{7}$ Department of General Surgery, The Second Affiliated Hospital of Nanjing Medical University, No.121 Jiang jia yuan, Nanjing 210011, China.}

Received: 22 November 2012 Accepted: 6 December 2012 Published: 13 December 2012

\section{References}

1. Jaffe ES, Harris NL, Stein H, Vardiman JW: WHO classification of tumours. Volume 3: pathology and genetics of tumours of haematopoietic and lymphoid tissue. Lyon: IARC Press; 2001.

2. Pongpruttipan T, Kummalue T, Bedavanija A, Khuhapinant A, Ohshima K, Arakawa F, Niino D, Sukpanichnant S: Aberrant antigenic expression in extranodal NK/T-cell lymphoma: a multi-parameter study from Thailand. Diagn Pathol 2011, 6:79.
3. Cao W, Liu Y, Zhang H, Wang S, Zhang L, Zhang L, Sun B: Expression of LMP-1 and cyclin D1 protein is correlated with an unfavorable prognosis in nasal type NK/T cell lymphoma. Mol Med Report 2008, 1:363-368.

4. Suzuki R, Suzumiya J, Yamaguchi M, Nakamura S, Kameoka J, Kojima H, Abe M, Kinoshita T, Yoshino T, Iwatsuki K, Kagami Y, Tsuzuki T, Kurokawa M, Ito K, Kawa K, Oshimi K, NK-cell Tumor Study Group: Prognostic factors for mature natural killer (NK) cell neoplasms: aggressive NK cell leukemia and extranodal NK cell lymphoma, nasal type. Ann Oncol 2010, 21:1032-1040

5. Kim SJ, Kim K, Kim BS, Kim CY, Suh C, Huh J, Lee SW, Kim JS, Cho J, Lee GW, Kang KM, Eom HS, Pyo HR, Ahn YC, Ko YH, Kim WS: Phase II trial of concurrent radiation and weekly cisplatin followed by VIPD chemotherapy in newly diagnosed, stage IE to IIE, nasal, extranodal NK/T-cell lymphoma: consortium for improving survival of lymphoma study. J Clin Oncol 2009, 27:6027-6032.

6. Yamaguchi M, Tobinai K, Oguchi M, Ishizuka N, Kobayashi Y, Isobe $Y$, Ishizawa K, Maseki N, Itoh K, Usui N, Wasada I, Kinoshita T, Ohshima K, Matsuno Y, Terauchi T, Nawano S, Ishikura S, Kagami Y, Hotta T, Oshimi K: Phase I/II study of concurrent chemoradiotherapy for localized nasal natural killer/T-cell lymphoma: Japan clinical oncology group study JCOG0211. J Clin Oncol 2009, 27:5594-5600.

7. Pagano L, Gallamini A, Trapè G, Fianchi L, Mattei D, Todeschini G, Spadea A, Cinieri S, Lannitto E, Martelli M, Nosari A, Bona ED, Tosti ME, Petti MC, Falcucci P, Montanaro M, Pulsoni A, Larocca LM, Leone G, Intergruppo Italiano Linfomi: NK/T-cell lymphomas 'nasal type': an Italian multicentric retrospective survey. Ann Oncol 2006, 17:794-800.

8. Takahashi E, Ohshima K, Kimura H, Hara K, Suzuki R, Kawa K, Eimoto T, Nakamura S, NK-cell Tumor Study Group: Clinicopathological analysis of the age-related differences in patients with Epstein-Barr virus (EBV)-associated extranasal natural killer (NK)/T-cell lymphoma with reference to the relationship with aggressive NK cell leukaemia and chronic active EBV infection-associated lymphoproliferative disorders. Histopathology 2011, 59:660-671.

9. Carbone A, Gloghini A, Dotti G: EBV-associated lymphoproliferative disorders: classification and treatment. Oncologist 2008, 13:577-585.

10. Cohen Jl, Bollard CM, Khanna R, Pittaluga S: Current understanding of the role of Epstein-Barr virus in lymphomagenesis and therapeutic approaches to EBV-associated lymphomas. Leuk Lymphoma 2008, 1:27-34

11. Kohrt H, Advani R: Extranodal natural killer/T-cell lymphoma: current concepts in biology and treatment. Leuk Lymphoma 2009, 50:1773-1784.

12. Yang QX, Pei XJ, Tian XY, Li Y, Li Z: Secondary cutaneous Epstein-Barr virus-associated diffuse large B-cell lymphoma in a patient with angioimmunoblastic T-cell lymphoma: a case report and review of literature. Diagn Pathol 2012, 7:7.

13. Kieff ED, Rickinson $A B$, et al: Epstein-Barr virus and its replication. In Fields virology, vol 2. 5th edition. Edited by Knipe DM. Philadelphia: Wolters Kluwer Health/Lippincott Williams \& Wilkins; 2007:2603-2654.

14. Shair KH, Bendt KM, Edwards RH, Bedford EC, Nielsen JN, Raab-Traub N: EBV latent membrane protein 1 activates Akt, NFkappaB, and Stat3 in B cell lymphomas. PLoS Pathog 2007, 3:e166.

15. Vrzalikova K, Vockerodt M, Leonard S, Bell A, Wei W, Schrader A, Wright KL, Kube D, Rowe M, Woodman CB, Murray PG: Down-regulation of BLIMP1a by the EBV oncogene, LMP-1, disrupts the plasma cell differentiation program and prevents viral replication in B cells: implications for the pathogenesis of EBV-associated B-cell lymphomas. Blood 2011, 117:5907-5917.

16. Chen F, Liu C, Lindvall C, Xu D, Ernberg I: Epstein-Barr virus latent membrane 2A (LMP2A) down-regulates telomerase reverse transcriptase (hTERT) in epithelial cell lines. Int J Cancer 2005, 113:284-289.

17. Pang MF, Lin KW, Peh SC: The signaling pathways of Epstein-Barr virus-encoded latent membrane protein $2 \mathrm{~A}$ (LMP2A) inlatency and cancer. Cell Mol Biol Lett 2009, 14:222-247.

18. Mancao C, Hammerschmidt W: Epstein-Barr virus latent membrane protein 2A is a B-cell receptor mimic and essential for B-cell survival. Blood 2007, 110:3715-3721.

19. Bieging KT, Swanson-Mungerson M, Amick AC, Longnecker R: Epstein-Barr virus in Burkitt's lymphoma: a role for latent membrane protein 2A. Cell Cycle 2010, 9:901-908. 
20. Portis T, Dyck P, Longnecker R: Epstein-Barr virus (EBV) LMP2A induces alterations in gene transcription similar to those observed in reedSternberg cells of Hodgkin lymphoma. Blood 2003, 102:4166-4178.

21. Liang X, Graham DK: Natural killer cell neoplasms. Cancer 2008, 112:1425-1436.

22. Friedrich M, Villena-Heinsen C, Reitnauer K, Schmidt W, Tilgen W, Reichrath $\mathrm{J}$ : Malignancies of the uterine corpus and immunoreactivity score of the DNA "mismatch-repair" enzyme human Mut-S-homologon-2. J Histochem Cytochem 1999, 47:113-118.

23. Mao Y, Zhang DW, Wen J, Cao Q, Chen RJ, Zhu J, Feng ZQ: A novel LMP1 antibody synergizes with mitomycin $C$ to inhibit nasopharyngeal carcinoma growth in vivo through inducing apoptosis and downregulating vascular endothelial growth factor. Int J Mol Sci 2012, 13:2208-2218.

24. $\mathrm{Ho} \mathrm{CH}$, Chen CL, Li WY, Chen CJ: Decoy receptor 3, upregulated by Epstein-Barr virus latent membrane protein 1, enhances nasopharyngeal carcinoma cell migration and invasion. Carcinogenesis 2009, 30:1443-1451.

25. Chen R, Zhang D, Mao Y, Zhu J, Ming H, Wen J, Ma J, Cao Q, Lin H, Tang Q, Liang J, Feng Z: A human Fab-based immunoconjugate specific for the LMP1 extracellular domain inhibits nasopharyngeal carcinoma growth in vitro and in vivo. Mol Cancer Ther 2012, 11:594-603.

26. Bollard CM, Gottschalk S, Leen AM, Weiss H, Straathof KC, Carrum G, Khalil M, Wu MF, Huls MH, Chang CC, Gresik MV, Gee AP, Brenner MK, Rooney CM, Heslop HE: Complete responses of relapsed lymphoma following genetic modification of tumor-antigen presenting cells and Tlymphocyte transfer. Blood 2007, 110:2838-2845.

27. Dargart JL, Fish K, Gordon LI, Longnecker R, Cen O: Dasatinib therapy results in decreased $B$ cell proliferation, splenomegaly, and tumor growth in a murine model of lymphoma expressing Myc and Epstein-Barr virus LMP2A. Antiviral Res 2012, 95:49-56.

28. Fox CP, Haigh TA, Taylor GS, Long HM, Lee SP, Shannon-Lowe C, O'Connor $\mathrm{S}$, Bollard CM, labal J, Chan WC, Rickinson AB, Bell Al, Rowe M: A novel latent membrane 2 transcript expressed in Epstein-Barr virus-positive NK- and T-cell lymphoproliferative disease encodes a target for cellular immunotherapy. Blood 2010, 116:3695-3704.

29. Du ZM, Kou CW, Wang HY, Huang MY, Liao DZ, Hu CF, Chen J, Yan LX, Hu LF, Ernberg I, Zeng YX, Shao JY: Clinical significance of elevated spleen tyrosine kinase expression in nasopharyngeal carcinoma. Head Neck 2012, 34:1456-1464.

doi:10.1186/1746-1596-7-178

Cite this article as: Mao et al:: LMP1 and LMP2A are potential prognostic markers of extranodal NK/T-cell lymphoma, nasal type (ENKTL). Diagnostic Pathology 2012 7:178.

\section{Submit your next manuscript to BioMed Central and take full advantage of:}

- Convenient online submission

- Thorough peer review

- No space constraints or color figure charges

- Immediate publication on acceptance

- Inclusion in PubMed, CAS, Scopus and Google Scholar

- Research which is freely available for redistribution

Submit your manuscript at www.biomedcentral.com/submit
C Biomed Central 